\title{
Choosing the Components of Distributed Information Systems as a Multi-Criteria Optimization Problem
}

\author{
Al-Samawi Yahya Ali \\ Al-Razi University \\ Yemen, Sana'a \\ Rabat st., Building G
}

\begin{abstract}
In this paper, author is presenting the task of choosing distributed systems' components as a task of multi-criteria optimization to help system analysts and designers to make informed decisions when building distributed systems that fulfil business tasks in desired efficient and reliability.
\end{abstract}

\section{General Terms}

Distributed Information Systems, System Analysis and Design, Multi-criteria Optimization.

\section{Keywords}

Distributed Systems, System Analysis and Design, Multicriteria Optimization, Operating Systems.

\section{INTRODUCTION}

Distributed Information System (DIS) is a fundamental part of any modern enterprises and is the basis of the control system that plays an important role in the enterprise. The development of business increases the amount of corporate information, resulting in more complex DIS by increasing the number of its components both software and hardware, their diversity, as well as variants of architecture, technologies used (CORBA, J2EE, MS .NET), etc. The large amount of DIS components makes the task of building DIS more complex due to the difficulties when choosing its components depending on the requirements of the enterprise. Listing the advantages and disadvantages of software and hardware components, architectures or technologies are not enough to make an informed decision in favor of any decision, meanwhile, system analysts uses a large number of selection criteria, which also differ in the degree of importance and priorities depending on the requirements of DIS.

\section{APPROACHES TO BUILD DIS}

This paper offers a solution to this problem by considering the task of choosing DIS components as a multi-criteria optimization problem due to the fact that system analyst has to consider many criteria when choosing DIS components.
There are usually two approaches used in construction of DIS:

1. Purchasing ready DIS: Enterprise Resource Planning (ERP) system, ready network topology, and preassembled clients and servers machines.

2. Building DIS by assembling the components from different manufacturers.

The first approach has serious shortcomings. Ready DIS is usually too expensive and may not have some important functions that are the requirements of the business. Experience in developing "ready" information systems helped to formulate an approach to the formation of corporate information systems, based on the "assembly" of the systems and 'components' of different manufacturers. Component architecture has been made possible through the support of leading software manufacturer's common standards for the design, development and technology component "assembly" of information systems implemented on different hardware and software platforms. In this paper, this approach is considered in conjunction with the principle of successive concessions to help system designer to make better decisions.

At present, the formation of DIS usually resort to a simple components comparison or features as described by the manufacturer or derived based on the testing conducted by specialized laboratories. It should also be emphasized while typically checking only one of the criteria, such as performance or reliability. The situation is due to the fact that still hasn't developed special techniques to jointly consider all the relevant criteria and their relative importance according to the requirements from DIS. Formation and development of such techniques will not only help developers create and maintain DIS, but the component manufacturers too.

\section{IMPORTANCE OF DIS}

The importance of improving the efficiency of selecting the DIS components is due to the value of DIS for the modern enterprise. The main indicator of the importance of the role of

\begin{tabular}{|c|c|c|c|c|}
\hline & $\begin{array}{r}2014 \\
\text { Spending }\end{array}$ & $\begin{array}{r}2014 \\
\text { Growth (\%) }\end{array}$ & $\begin{array}{r}2015 \\
\text { Spending }\end{array}$ & $\begin{array}{r}2015 \\
\text { Growth (\%) }\end{array}$ \\
\hline Devices & 696 & 3.8 & 732 & 5.1 \\
\hline Data Center Systems & 141 & 0.8 & 143 & 1.8 \\
\hline Enterprise Software & 317 & 5.8 & 335 & 5.5 \\
\hline IT Services & 956 & 2.7 & 981 & 2.5 \\
\hline Telecom Services & 1,626 & -0.1 & 1,638 & 0.7 \\
\hline Overall IT & 3,737 & 1.9 & 3,828 & 2.4 \\
\hline
\end{tabular}

Fig 1: Worldwide IT spending forecast (Billions of U.S. Dollars) 
IT in all sectors of the industry is that the efficiency of business operations depends directly on IT departments. This conclusion is supported by figures of the growth of companies' spending on enterprise software shown in figure 1 [1] and the magnificent growth of investment in information systems in the last decades (figure 2) [2].

The characteristic of Distributed Information System depends on the effectiveness and validity of the choice of its components when it becomes necessary to expand the DIS by adding new components, clients, servers, communications equipment, etc. Reasonably selected DIS architecture allows you to add and remove the old components with minimal cost and in the shortest possible time.

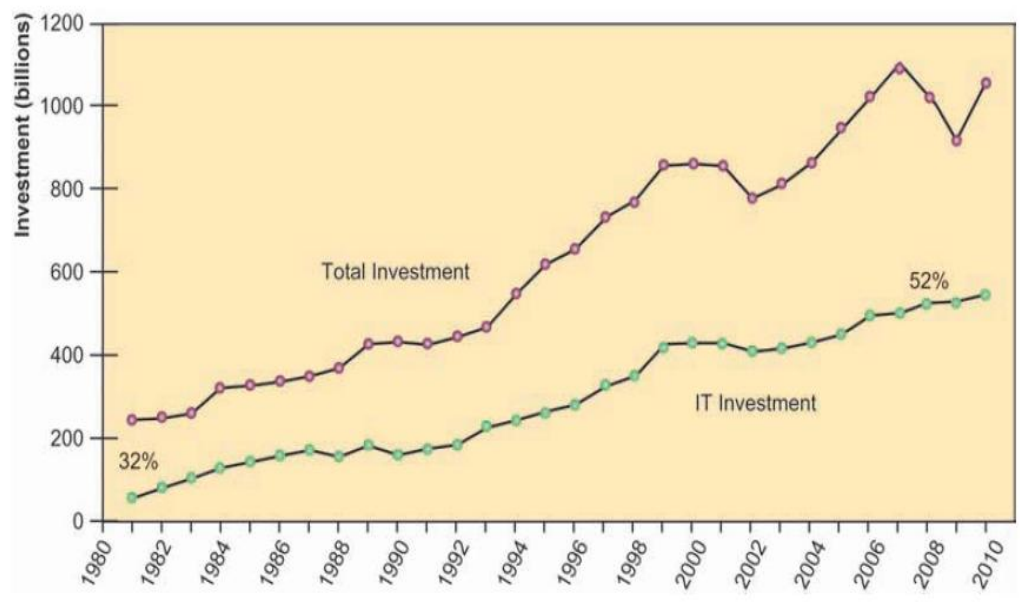

Fig 2: Information technology capital investment, defined as hardware, software, and communications equipment, grew from 32 percent to 52 percent of all invested capital between 1980 and 2011.

\section{COMPONENTS OF DIS}

The problem of choosing a DIS component occurs at different stages of life cycle (LC) of DIS: at the design and creation stages of DIS development LC (reengineering); when it is necessary to improve DIS in line with the new business requirements or a need to move from one platform or technology to another; at maintenance stage of the system development when it is necessary to replace any component that has outdated or failed and so on.

This problem occurs as such for the following reasons: there is a great variety of DIS architectures; there are a large number of DIS components software and hardware, as well as a large number of alternatives available on the market made by different manufacturers.

On this basis, to solve this problem, system analyst may consider it as a problem of multi-criteria optimization, which will justify the creation of an efficient DIS due to the choice of the components that best fulfills the DIS functions, given the options of construction and evaluation criteria.

To understand the problems, following well be an overview of some main components of DIS with explanations to what they are and the most important parts in them.

On this basis, to solve this problem, system analyst may consider it as a problem of multi-criteria optimization, which will justify the creation of an efficient DIS due to the choice of the components that best fulfills the DIS functions, given the options of construction and evaluation criteria.
To understand the problems following well be an overview of some main components of DIS with explanations to what they are and the most important parts in them.

The rising level of DIS complexity led to different architectures. This in turn led to the emergence of various technologies in software development. Examples include technologies of CORBA, MS .NET from Microsoft and J2EE from Sun Microsystems (Sun Microsystems was purchased by Oracle company). These technologies are meant to help DIS designers to concentrate on solving the main tasks of data processing without bothering themselves with routine programming tasks such as creating a connection, finding components, synchronization etc.

Figure 3 shows the main components of DIS software that has been built in terms of one of the most popular technologies: CORBA, J2EE or MS .NET. This shows the complexity of these technologies that provide DIS software developers with standard services that help in building the DIS programs easier with fewer errors and fulfill the tasks with best quality $[3,4]$.

Selection of any one technology is also challenging due to the large number of criteria, the large number of components within them, the large amount of services that they provide and how do they provide them. 
Client Machine

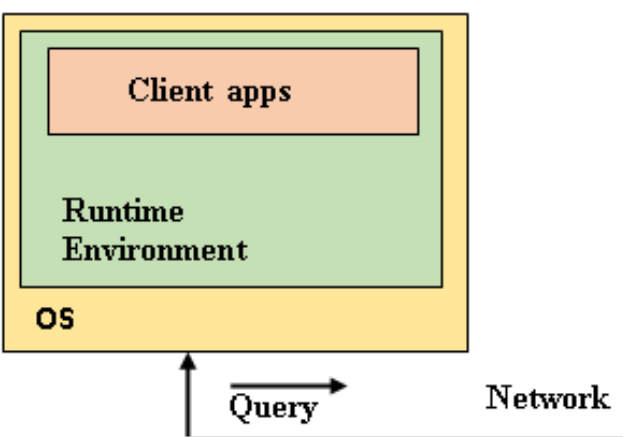

Server Machine

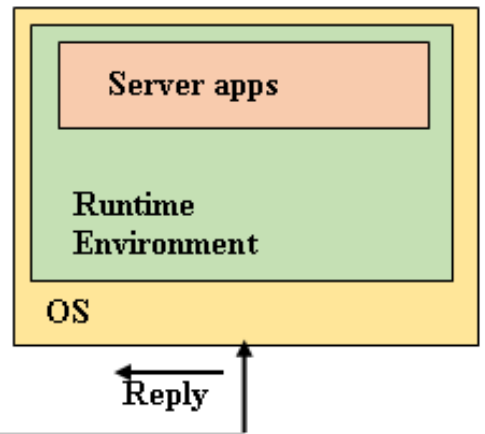

Fig 3: Software of DIS according to main DIS technologies (CORBA, .NE, J2EE)

For those technologies the following criteria are usually consider:

- $\quad$ Scalability -> has to be maximized.

- Reliability -> should be maximum

- Multiplatform -> maximum

- $\quad$ Cost $->$ should be minimum
Another important component of DIS that system designer meets when building DIS is choosing between the DIS architectures. There are three architectures of DIS: 2-tier, 3tier and $\mathrm{N}$-tier architectures [5].Figure 4 shows an example of $\mathrm{N}$-tier architecture with dedicated Web and application servers.

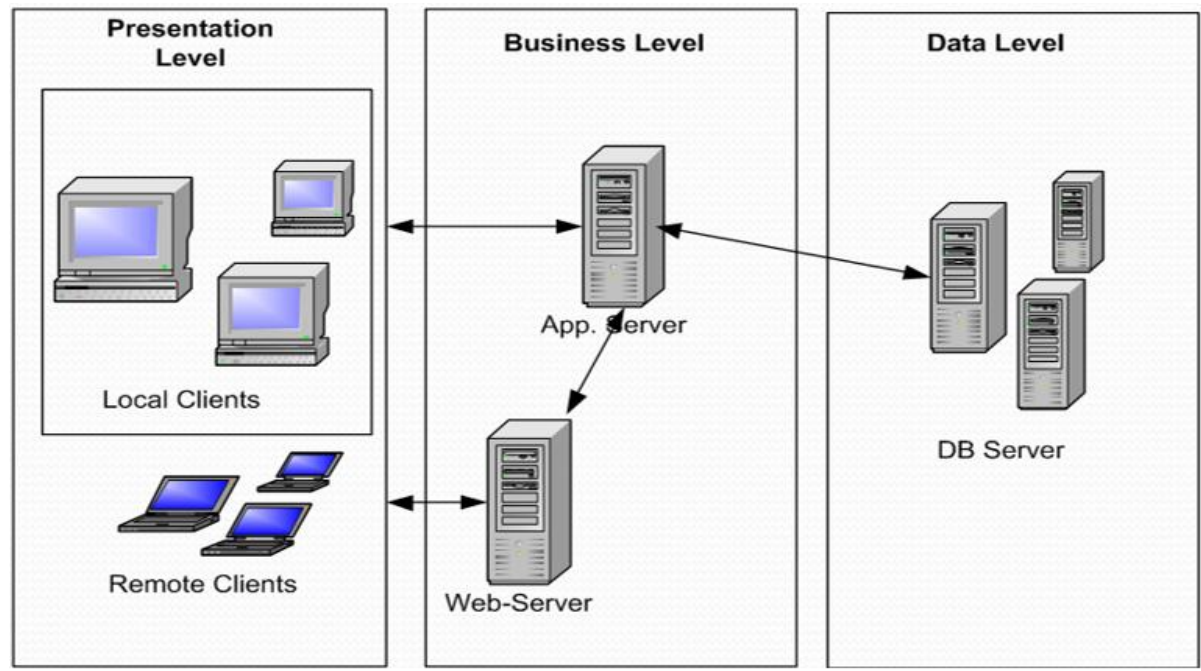

Fig 4: Multi-tier architecture with dedicated Web server and application server

For these architectures the following criteria are usually considered:

- $\quad$ Scalability -> maximum

- $\quad$ Reliability $\rightarrow>$ should be maximum

- $\quad$ Load on the network -> should be minimum

- $\quad$ Cost $->$ should be minimum

Figure 5 shows the hardware of DIS that consists of client machines, servers and communication devices. Choosing any of them also requires comprehensive information of their interior components and properties such as CPU, the amount of RAM and other features [6].

The last key component of DIS that is considered is the platform. There is a tough competition between two types of operating systems (OS): Windows or Linux. Choosing any one among them is an important task that system designer has to solve. The Operating System is controlling the resources of computers by providing many services for client and server applications and it affects the performance of the whole DIS. 


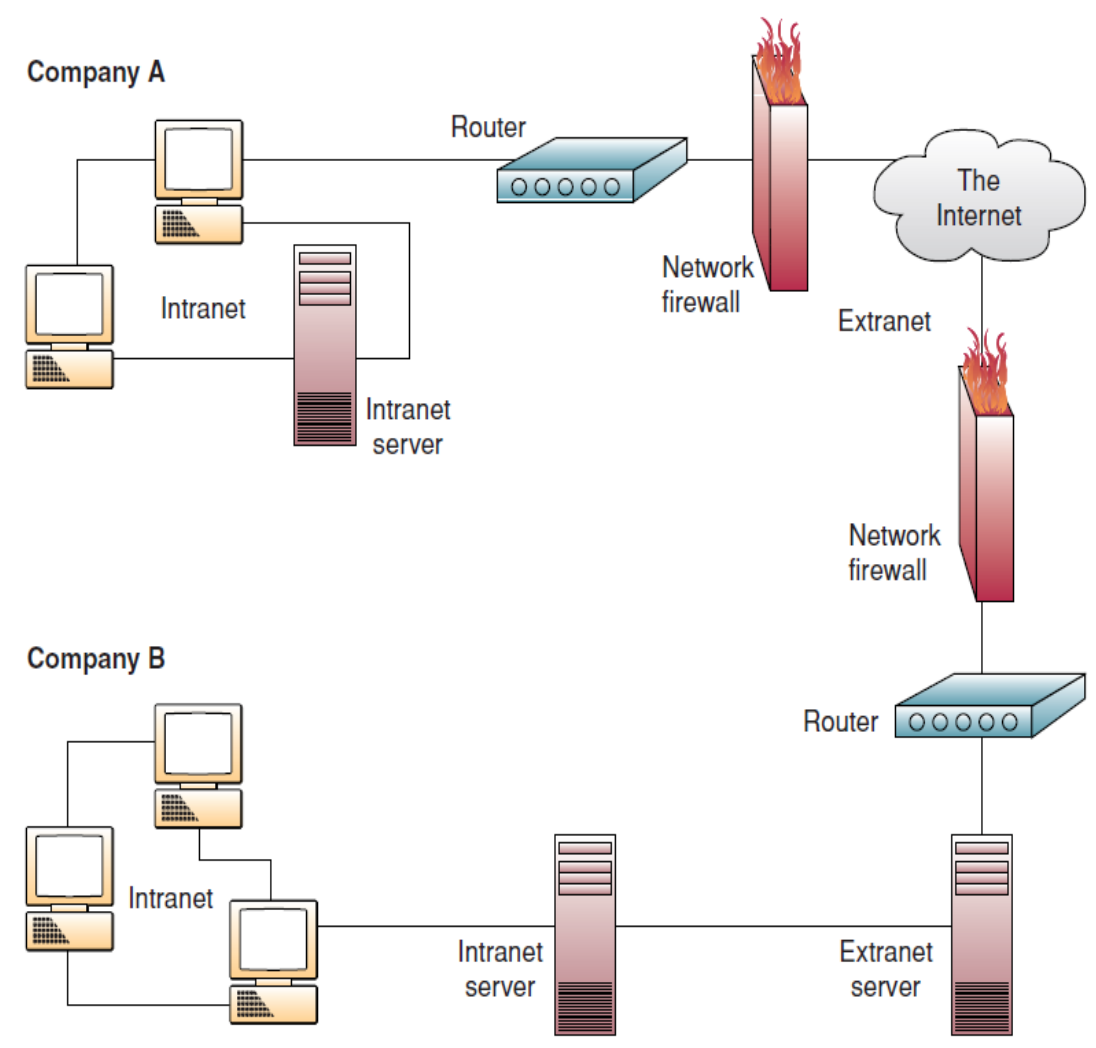

Fig 5: Main DIS hardware components

The main criteria for choosing among Operating System are:

- $\quad$ Performance $->$ should be maximum

- Reliability $\rightarrow$ maximum

- $\quad$ Security $\rightarrow>$ should be maximum

- $\quad$ Cost $->$ minimum

\section{CHOOSING THE RIGHT DIS COMPONENT}

What has been said leads to the main topic of this paper: solving the problem of choosing DIS component as the task of multi-criteria optimization. This enables the use of the correct systematic methods for deciding in favor of those components of DIS that provide the best of its functionality under business conditions. This will improve the DIS by improving the quality of decisions made when selecting their components software and hardware, as well as architectures and technologies for construction.

As mentioned earlier, the task of choosing the DIS component can be solved as a problem of multi-criteria optimization; selected for this method of convolution of the vector criterion. In this method, an expression for the integral criterion takes the form

$$
\operatorname{optim} \bar{F}=\max _{F \in W_{F}^{K}}\left[\left(\prod_{q=1}^{l} f_{q}\right)\left(\prod_{q=l+1}^{k} f_{q}\right)^{-1}\right]
$$

Where $f_{q}, q=\overline{1, l}-$ local criteria that needs to be maximized;

$$
q=\overline{l+1, k}-\text { Criteria which must be minimized. }
$$

In $[7,8]$ exists all details about algorithm of this method to solve such task. All what is needed is defining the criteria that have to be considered when choosing the right DIS component. then get values for each criteria (these values can be retrieved from special laboratories that are specialized in testing of DIS components) and then solve the problem.

Below are the results for 2 variants of homogeneous DIS under only Windows Operating System or Linux Operating System. The following data is based on tests results provided in $[9,10]$ and prices from many specialized sites. Cost includes: purchase, implementation and adding new client.

Table 1: Data for homogeneous DIS OS

\begin{tabular}{|l|c|c|}
\hline Criteria & DIS under Windows & DIS under Linux \\
\hline Cost & $17418 \$$ & $18418.32 \$$ \\
\hline Performance & 1.42 & 1.17 \\
\hline Reliability & 7.6 & 8.3 \\
\hline
\end{tabular}


Table 2: Recommendations for DIS under only windows or Linux

\begin{tabular}{|c|c|c|c|}
\hline Variants & OC & $\mathbf{F}$ & Recommendations \\
\hline \multirow{2}{*}{$\begin{array}{l}\text { Cost and scalability is more important than } \\
\text { performance and reliability }\end{array}$} & Windows & 0.08 & Yes \\
\hline & Linux & 0.07 & No \\
\hline \multirow{2}{*}{$\begin{array}{l}\text { Performance and reliability are more important than } \\
\qquad \text { cost }\end{array}$} & Windows & 0.44 & Yes \\
\hline & Linux & 0.31 & No \\
\hline
\end{tabular}

The result shows that the use of Windows for constructing economical DIS is preferably higher than the DIS whose construction is based on Linux. Despite the fact that the cost of acquisition of the Linux operating system is several times smaller than Microsoft Windows, the cost of development and maintenance of DIS built upon it is more than using of
Windows. At the same time, Windows outperforms Linux as the best platform for building DIS and provides better performance and security as they are the central requirements for the DIS.

Below are the data and recommendations for 2 variants of heterogeneous DIS under Windows server or Linux server.

Table 3: Data for heterogeneous DIS

\begin{tabular}{|c|c|c|}
\hline Criteria & Windows-server & Linux-server \\
\hline Cost & $19612.4 \$$ & $2624.32 \$$ \\
\hline Performance & 1.42 & 1.17 \\
\hline Reliability & 7.6 & 8.3 \\
\hline
\end{tabular}

Table 4: Recommendations for heterogeneous DIS

\begin{tabular}{|c|c|c|c|}
\hline Variant & OS & F value & Recommendations \\
\hline \multirow{2}{*}{$\begin{array}{c}\text { Cost is more important than performance and } \\
\text { reliability }\end{array}$} & Windows & 0.07 & No \\
\cline { 2 - 4 } & Linux & 0.5 & Yes \\
\hline \begin{tabular}{c} 
Performance and reliability is more important $\begin{array}{c}\text { No } \\
\text { than the cost }\end{array}$ \\
\cline { 2 - 4 }
\end{tabular} & Windows & 0.42 & Yes \\
\hline
\end{tabular}

This shows that the heterogeneous DIS under Linux-server is a preferable DIS than DIS under Windows Server. Therefore, when referring to the cost as the main criterion in the construction of heterogeneous DIS it is preferable to use Linux as a server operating system. Also, when the criteria of performance and reliability are the main when building heterogeneous DIS, it is preferable to use Linux as a server operating system.

\section{CONCLUSION}

Nowadays, information processing is distributed throughout the network of several computers rather than limited to a single computer. Many small and large scale organizations are implementing distributed information systems in the communication fields. The system designers have to deal with many problems while designing an appropriate DIS for the institutions. One of the most important issue meanwhile is to solve the problem of making the appropriate decision when choosing among components of DIS to build DIS that has the best characteristics among many criteria of choosing. The system designer must ensure that proposed design will have maximum scalability and reliability and should cost as low as possible. Solving this problem as a multi-criteria optimization task helps system designer be sure of choosing the best components of DIS with consideration of all possible criteria and their importance. As far as Windows and Linux servers are concerned, the Windows platform is best and cost effective for building the homogeneous DIS as it provides better security and performance. In case of heterogeneous DIS application, the Linux server is a best platform for the purpose. Linux server is the cost effective solution for heterogeneous DIS and it also gives the higher reliability and better performance in comparison to the Windows server platform.

\section{ACKNOWLEDGMENTS}

My thanks to my supervisor in the years of my postgraduate education Professor Doctor of Technical Sciences Alexie Vladimirovich Kostrov who had contributed towards the development of my knowledge and education.

\section{REFERENCES}

[1] Global IT spending on pace to grow $2.4 \%$ in 2015: Gartner. http://www.ft.lk/2015/01/21/global-it-spendingon-pace-to-grow-2-4-in-2015-gartner/

[2] Laudon, K. C., Laudon J. P. 2014 Management Information Systems: MANAGING THE DIGITAL FIRM, 13th Edition. Pearson Education Limited

[3] Tanenbaum, A. S., Steen M. V. 2006 Distributed Systems: Principles and Paradigms, Prentice Hall

[4] Coulouris, G., Dollimore, J, Kindberg, T, Blair, G. 2012 Distributed Systems: Concepts and Design, AddisonWelsey

[5] Dosyukov , S. 2003 Distributed Information Systems. From A to Z. - Part I. Introduction, http://edn.embarcadero.com/article/30025 
International Journal of Computer Applications (0975 - 8887)

Volume 150 - No.5, September 2016

[6] Marakas, G.M., O’Brien, J.A. 2013, M. Introduction to Information Systems, McGraw-Hill

[7] Костров, А. В. 2008 Основы информационного менеджмента. - 2-е изд., перераб. и доп. - М.: Финансы и статистика,

[8] Гасов, В. М. 1991 Системное проектирования взаимодействия человека с техническими средствами
[9] Аль-Самави, Я. А. 2007 Выбор платформы для построения информационных систем . Алгоритмы, методы и системы обработки данных: сборник научных статей под ред. С.С. Садыкова, Д. Е. Андрианова - М.: ООО «Центр информационных технологий в природопользовании», , с. 9-13.

[10] Аль-Самави, Я. А. 2012 Методы Совершенствования Распределенных Информационных Систем, Lambert Academic Publication 